of food available to fish than was formerly realized, and that at least in limited areas such pests might be greatly reduced in numbers by specialized trawling.

To summarize, the following are among the main considerations that emerged from the symposium:

(1) The rapid rise in world population makes it doubly important that there should be increased production and much better utilization for human food of land fauna, both domestic and wild, and of sea fauna.

(2) The potentialities of such increased production are large if present agricultural, animal husbandry and fisheries knowledge is effectively applied, and if the utilization of wild animals is conducted intelligently and under adequate control; these potentialities are immense if sufficient research effort is directed towards the further acquisition of knowledge in these fields, particularly in that of marine biology.

(3) The rate of progress in improving the protein status of malnourished populations will depend largely on indigenous decisions to correlate their farming and their fisheries policy with indigenous nutritional neods, and actively and continuously to stimulate the intelligent knowledgeable local production of fish, flesh and fowl.

The proceedings of the symposium will be published by the Institute of Biology (41 Queen's Gate, London, S.W.7).
H. D. KAY

\title{
FIFTH INTERNATIONAL CONGRESS OF BIOCHEMISTRY
}

$\mathrm{T}$ HE fifth International Congress of Biochemistry, organized by the U.S.S.R. Biochemical Society and sponsored by the International Union of Biochemistry and the Academy of Science of the U.S.S.R., was held in Moscow during August 10-16, under the presidency of Academician A. I. Oparin. The scientific sessions were held in the imposing building of the University of Moscow which stands on the Lenin Hills and overlooks the historic city. The number of registered participants, about 4,500 together with an additional 1,000 or so guests of the Organizing Committee, was larger than any previous congress, and it seems that each congress, from the first, which was held in Cambridge in 1949, to the present one in Moscow, attracts more and more workers who are interested in one or many aspects of the broad subject of biochemistry.

The congress held its opening ceremony in the impressive Palace of Sports of the Central Lenin Stadium and the session closed with a masterly lecture on "The Structure and Function of Subcellular Particles", by Prof. D. E. Green (United States). Unfortunately, poor projection facilities reduced the enjoyment of many participants who were not fortunate enough to be seated near the front of the huge lecture hall. The plenary session was followed by a most enjoyable concert given by the Moscow Symphony Orchestra.

The scientific programme which followed included a series of symposia, and between two and three thousand original contributions given under the auspices of twenty-eight sections. The main congress symposia were held in the large assembly hall of the University or in auditoria of ample seating capacity and were well attended throughout. The symposia covered the following subjects: (1) Biological Structure and Function at the Molecular Level (president, M. F. Perutz, Great Britain); (2) Functional Biochemistry of Cell Structures (O. Lindberg, Sweden); (3) Evolutionary Biochemistry (S. Ochoo, United States); (4) Molecular Basis of Enzyme Action and Inhibition (P. Desnuelle, France); (5) Intracellular Respiration: Phosphorylating and Non-Phosphorylating Reactions (E. C. Slater, Holland); (6) Mechanism of Photosynthesis (H. Tamiya, Japan); (7) Biosynthesis of Lipids (G. Popják, Great Britain); (8) Biochemical Principles of Food Industry (E. Pyanowski, Poland). The main sperkers in these sessions were allowed up to forty minutes to develop their subject and the subsequent speakers fifteen minutes, a half to three-quarters of an hour being set aside at the end of the session for discussion. The time proved to be adequate, and the discussions were usually lively. The arrangements for simultaneous translations in these meet ings were excellent.

Among the many important communications given in the symposia Dr. Britton Chance's demonstration of a new effect in the field of intracellular respiration predicted on theoretical grounds some years ago by Sir Hans Krebs, namely, the reversal of the direction of electron transfer in isolated mitochondria occurring on the addition of adenosine triphosphate and leading to a reduction of pyridine nucleotide was particularly noteworthy; as were Prof. A. L. Lehninger's report on a preparation of hitherto unrecognized components of the chain of oxidative phosphorylation and their relation to the swelling and contraction of mitochondria, and Prof. Lynen's account of the advances he and his colleagues had recently made in the understanding of the role of $(+)$-biotin as a coenzyme of carbon dioxide fixation and transcarboxylation. Prof. E. P. Kennedy (United States) gave an outstanding lecture on lipid biosynthesis. There were, of course, many other new and interesting aspects of fundamental problems presented at the congress, but the author, in common with other participants, was able to hear only a small part of them. Pre-prints of the main congress lectures and of the contributions to the symposia were available to participants before the meeting.

Probably the largest part of the scientific programme was associated with the activities of the twenty-eight sections which held their meetings and discussions in nearly as many rooms scattered throughout the very large University building and in the Departments of Physics and of Chemistry situated a fow minutes walk from the main building. Two of the Sections, those concerned with Immunochemistry and the Biochemistry of Malignant Tumours, held their meetings in the Sternberg Institute of Astronomy, which was unfortunately about a 15-min. walk away from the site of the main congress activities.

Each section had its own interpreter, and language difficulties were thereby reduced to a minimum. Abstracts of the short communications were available in the form of a separate book, and where the text 
was submitted in Russian, an English translation was also provided.

A Russian version of the whole of the congress proceedings is to be published by the U.S.S.R. Academy of Science and a corresponding publication in English ( 10 vols.) will be made by the Pergamon Press, Ltd. These volumes are in course of prepara. tion.

There was a useful display of scientific apparatus originating from fourteen countries, and an attractive exhibition of modern books dealing with all aspects of biochemistry and published in many different countries.

A significant achievement, admittedly not directly a part of the congress, was the appearance of the report of the Commission on Enzymes, of the Inter. national Union of Biochemistry. This document, which is the first official attempt to put enzyme nomenclature on an international basis, is the work of a group of acknowledged experts under the chair manship of Dr. Malcolm Dixon of the University of Cambridge. It makes an outstanding and muchneeded contribution to modern enzymology.

Most of those attending the congress were accom. modated in the student quarters of the University or in two of the largest hotels in Moscow, Hotel Ukraine and Hotel Mockba. The problems which arose through accommodating so many visitors in so short a time were finally sorted out, although only after some participants had suffered considerable inconvenience. It was generally agreed, however, that once one had found the accommodation for which one had originally asked, the standard of comfort was all that could be desired. Transport between the University and hotels was well maintained throughout the congress by an excellent bus service. The hosts were most generous with their hospitality and Academician Oparin gave a series of most delightful receptions to the participants in the symposia. There was a series of interesting tours arranged by Intourist.

The participants from the Commonwealth much appreciated the kindness of Sir Frank Roberts, the British Ambassador in the U.S.S.R., who held a reception so that British participants might entertain their Russian colleagues who had given so much time and made so much effort to make the congress the scientific success it undoubtedly was.

Plans for the next international congress are by now under serious consideration, and it must be in the minds of the organizers that it will be attended by an even greater number of scientists than wore present in Moscow this year. It is clearly impossible for any one person to attend more than a few of the sessions, and it is also evident that ten minutes for the presentation and discussion of each ordinary communication is inadequate. It might, therefore, be worth considering whether a more satisfactory procedure for use at future congresses would be to restrict the number of speakers, without limiting the number of papers communicated by title and circulated in the form of abstracts. A limitation of this kind would also reduce the number of simultaneous sessions, which, it is generally agreed, are far too many at large international congresses in which there are only four or five days to present and discuss all the papers submitted by the participants.

Perhaps to-day the long notice required to publish and pre-circulate abstracts of the scientific contributions makes it unlikely that anything really new will be announced at an international congress. Probably the most valuable function of such a meeting is to bring workers together to take part in symposia and to engage in informal discussion, where they can estimate their progress or thrash out their differences or misunderstandings in small rooms or quiet corners which are set apart for such gatherings, but which are within easy reach of the main meeting rooms and where light refreshments would be available.

The fifth International Congress in Biochemistry was the largest congress yet held in the U.S.S.R. and it was obviously well supported by the Russian Government. It is generally recognized that the more biological aspects of science in the U.S.S.R. have up to the present received far less attention than have the physical and engineering sciences; but the impression gained was that there is a growing aware. ness of this relative neglect, and that there was an awakening to the fact that biochemistry and other biological subjects must in future receive the support they so justly deserve and need.

The closing plenary session was especially noteworthy for the outstanding and informative lecture on "Proteins, their Function and Structure" given by Prof. F. Sorm (Czechoslovakia). This was followed by a number of short addresses of appreciation by delegates from several countries, after which the president closed the proceedings and formally announced that the next congress would be held in New York in July 1964.

W. T. J. Morgan

\title{
ATTENTION AND IN-ATTENTION IN NEUROPHYSIOLOGY*
}

\author{
By L. GOLDIE $†$ and Mrs. J. M. GREEN \\ Institute of Psychiatry, Maudsley Hospital, London, S.E.5
}

$\mathrm{R}$ ECENT advances in neurophysiological techniques have enabled objective evidence to be readily and reliably obtained during long recordings, and cortical and subcortical electrical events to be examined.

Despite this there has beon little increase in the understanding of the working of the human brain

* Substance of a paper read at the Ninth Latin American Congress of Neurosurgery during a symposium on the "Physiological Basis of Mental Activity", October 1961 .

+ Present address: The Fountain and Carshalton Group, Queen Mary's Hospital for Children, Carshalton, Surrey. as it relates to mental experience. Much experimental work in the past has centred on the animal brain. Transposition of the theories derived from such studies to the special problem of the human brain has resulted in the formulation of certain philosophical devices to overcome complexities by narrowing the observations within certain controllable limits.

But philosophical issues must inevitably be subjected to the test of practical experiments. The Dualists, in supporting a metaphysical theory of reality, regarded the mind as having an independent 